\title{
PENGARUH PENGUNGKAPAN CSR TERHADAP KINERJA KEUANGAN PT. ASAHIMAS FLAT GLASS TBK
}

\author{
Sinta Ayu Kelana ${ }^{1}$, Ramdany ${ }^{2}$ \\ ${ }^{1}$ STIE Muhammadiyah Jakarta, sinta@ stiemj.ac.id \\ ${ }^{1}$ STIE Muhammadiyah Jakarta, ramdany2012@gmail.com
}

\begin{abstract}
ABSTRAK
Pengungkapan CSR merupakan salah satu upaya yang dilakukan perusahaan untuk membangun kepercayaan kepada stakeholder agar investor tertarik untuk menanamkan modalnya di perusahaan tersebut. Tujuan penelitian ini adalah untuk menganalisa pengungkapan tanggungjawab sosial dan lingkungan yang akan diuji apakah terdapat pengaruh terhadap kinerja keuangan perusahaan. Kinerja keuangan perusahaan dalam penelitian ini di proxy dengan variabel ROA. Dalam penelitian ini, jenis data yang digunakan adalah data sekunder yang diambil dari laporan keuangan tahunan yang telah di publikasikan di Bursa Efek Indonesia. Penelitian ini menggunakan sampel data 6 tahun periode 2011 sampai dengan 2016. Hasil penelitian ini menunjukkan bahwa tingkat pengungkapan tanggung jawab sosial dan lingkungan berpengaruh terhadap ROA.
\end{abstract}

Kata kunci : Tingkat pengungkapan CSR, ROA

\begin{abstract}
CSR disclosure is one of the efforts made by the company to build trust in stakeholders so that investors are interested in investing their capital in the company. The purpose of this study is to analyze the disclosure of social and environmental responsibility that will be tested whether there is an influence on the company's financial performance. The financial performance of the company in this study is proxied by the variable ROA. In this study, the type of data used is secondary data taken from annual financial reports that have been published on the Indonesia Stock Exchange. This study uses a data sample of 6 years from 2011 to 2016. The results of this study indicate that the level of social and environmental responsibility disclosure affects ROA.
\end{abstract}

Keywords: CSR disclosure level, ROA.

\section{PENDAHULUAN}

Perusahaan selalu berusaha untuk mempertahankan keunggulan bisnisnya agar dapat menghasilkan laba yang diinginkan, serta membuat nilai perusahaan menjadi lebih baik. Hal ini dilakukan agar investor tertarik dan menanamkan modalnya di perusahaan tersebut. Seorang investor sebelum melakukan investasi akan melihat kinerja perusahaan, untuk memastikan modal yang ditanamkan mampu memberikan tingkat pengembalian (rate of return) yang diharapkan. Salah satu cara mengetahui kinerja perusahaan adalah dengan menganalisis rasio profabilitas perusahaan untuk mengendalikan laba yang diperoleh perusahaan (Freddy Rangkuti, 2005:148).

Perkembangan dalam dunia bisnis secara global telah diikuti oleh peningkatan kesadaran publik akan tanggung jawab perusahaan. Kini perusahaan tidak hanya bertujuan mencapai profit dan pertumbuhan, tetapi juga keberlangsungan dimana untuk mencapainya, perusahaan dituntut untuk menunjukkan rasa tanggung jawab dan keperdulian terhadap isu-isu sosial baik di dalam perusahaan maupun yang berkembang di dalam mansyarakat. 
Untuk mencapai keberlangsungan (sustainability), muncul konsep yang dikenal sebagai Corporate Social Responsibility (CSR). CSR merupakan suatu konsep teritegrasi yang menggabungkan aspek bisnis dan sosial dengan selaras agar perusahaan dapat membantu tercapainya kesejahteraan stakeholders, serta dapat mendapat profit yang maksimum bagi perusahaan. CSR sangat erat hubungannya dengan pembangunan berkelanjutan (Sustainable Development). Pembangunan berkelanjutan mencakup tiga hal kebijakan, yaitu pembangunan ekonomi, pembangunan sosial, dan perlindungan lingkungan.

Menurut John Elkington (Wibisono, 2007) CSR dapat dijalankan melalui "Triple Bottom Line". Konsep tersebut mengakui jika perusahaan ingin suistain, maka perlu memperhatikan 3P yaitu memberikan laba yang menguntungkan perusahaan (profit), memberikan kontribusi positif kepada masyarakat (people) dan ikut serta dalam menjaga kelestarian lingkungan (planet). Kontribusi positif yang dilakukan kepada masyarakat dapat berupa penekanan pada pembangunan sosial dan pembangunan kapasitas masyarakat sehingga dapat menggali potensi masyarakat yang berada di sekitar lingkungan perusahaan untuk maju dan berkembang, dapat menciptakan peluang-peluang sosial ekonomi masyarakat juga menyerap tenaga kerja dengan kualifikasi yang diinginkan. Selain itu, trust (rasa percaya) dan sense of belonging (rasa memiliki) akan terbentuk dari masyarakat sehingga masyarakat merasakan adanya manfaat atas kehadiran perusahaan.

Menurut Dazahro (2012) menyatakan bahwa program CSR merupakan investasi bagi perusahaan demi pertumbuhan dan keberlanjutan (sustainability) perusahaan dan bukan lagi dilihat sebagai sarana biaya (cost centre) melainkan sebagai sarana meraih keuntungan (profit centre). Program CSR merupakan komitmen perusahaan untuk mendukung terciptanya pembangunan berkelanjutan (sustainable development).

CSR saat ini bersifat wajib bagi perusahaan untuk menerapkannya. Hal ini diatur dalam Undang-Undang Nomor 40 Tahun 2007 tentang Perseoran Terbatas (UU PT) disahkan pada 20 Juli 2007. Tanggung jawab sosial dan lingkungan terdapat di pasal 74 dalam UU PT. Isi pasal 74 menyebutkan bahwa "Perseroan yang menjalankan kegiatan usahanya di bidang dan/atau berkaitan dengan sumber daya alam wajib melaksanakan tanggung jawab sosial dan lingkungan". Dengan adanya Undang-undang ini, perusahaan wajib untuk melaksanakannya, sehingga industri dan korporasi berperan untuk mendorong pertumbuhan ekonomi yang sehat dengan mempertimbakan faktor lingkungan hidup.

Undang-undang tersebut juga mewajibkan semua perseroan untuk melaporkan pelaksanaan tanggung jawab tersebut didalam Laporan Tahunan, seperti dijelaskan pada pasal $66 \mathrm{UU}$ No.40/2007. Adanya kewajiban tersebut merupakan pencerminan dari perlunya akuntabilitas perseroan atas pelaksanaan kegiatan CSR. Dengan adanya transparansi dan akuntabilitas, tentunya tujuan akhir yang diharapkan adalah bahwa perseroan dengan kesadaran sendiri akan melaksanakan kegiatan CSR.

Tanggung jawab sosial dan lingkungan perusahaan dilaporkan dalam bentuk laporan keuangan tahunan perusahaan, yang akan dipertanggungjawabkan pada saat RUPS. Laporan keuangan perusahaan sangat berguna bagi investor dalam pengambilan keputusan. Bila manfaat yang akan diperoleh dengan pengungkapan informasi tersebut lebih besar dibandingkan biaya yang dikeluarkan untuk pengungkapannya, maka perusahaan akan dengan sukarela mengungkapkan informasi tersebut.

Dalam pelaksanaan CSR terjadi banyak masalah yang dihadapi, seperti masih belum tersosialisasikannya program CSR dengan baik di masyarakat sekitar perusahaan. Program CSR masih sering kali belum tepat sasaran dalam melakukan pertanggung jawaban perusahaan. Oleh karena itu peneliti ingin membantu dalam memberikan kontribusi dengan melakukan penelitian tentang CSR.

Berdasarkan uraian diatas, maka tujuan penulis untuk menganalisis Pengaruh Pengungkapan CSR Terhadap Kinerja Keuangan pada perusahaan PT. ASAHIMAS FLAT GLASS Tbk. 


\section{KAJIAN LITERATUR}

CSR

CSR perusahaan yaitu untuk mengkomunikasikan dampak-dampak sosial dan lingkungan dari keseluruhan aktifitas yang dilakukan oleh perusahaan (Heriyanto, 2009). Pengukuran CSR disclosure diperoleh dari hasil assesment yang dilakukan peneliti melalui content analysis atas pengungkapan sustainability report yang dilakukan oleh masing-masing perusahaan sampel pada laporan tahunan perusahaan dengan mengimplementasikan GRI guidelines tahun 2006. Indeks GRI guidelines tahun 2006 yang digunakan dalam penelitian ini terdiri dari 5 indikator, yaitu :

1. Indikator Kinerja Ekonomi.

2. Indikator Kinerja Bidang Lingkungan.

3. Indikator Kinerja Hak Asasi Manusia.

4. Indikator Kinerja Kemasyarakatan.

5. Indikator Kinerja Tanggung Jawab dari Dampak Produk.

Variabel ini dapat diukur dengan melihat banyaknya item pengungkapan sosial yang terdapat dalam laporan tahunan perusahaan. Jika perusahaan menyajikan pengungkapan sosial diberi skor satu (1), namun jika tidak menyajikan diberi skor nol (0). Jumlah item yang dipenuhi perusahaan menurut GRI sebanyak 79 item (Wati, 2018).

Dimana :

$$
\text { CSRIj }: \frac{\Sigma_{\mathrm{Xij}}}{\mathrm{Nij}}
$$

CSRIj : Corporate Social Responsibility Disclosure Indeks Perusahaan.

ROA

$\Sigma X i j$ : Jumlah pengungkapan CSR Perusahaan.

Nij : Jumlah item untuk perusahaan 79 indikator.

Penelitian ini menggunakan rasio Return On Assets (ROA) untuk mengetahui tingkat profitabilitas perusahaan. Secara matematis rasio tersebut ditulis sebagai berikut :

$$
\text { ROA : } \frac{\text { Laba Setelah pajak }}{\text { Total Aktiva }} \times 100 \%
$$

Tabel 1. Pengukuran Operasional Variabel Penelitian

\begin{tabular}{|l|l|l|}
\hline Variabel & Pengukuran & Skala \\
\hline $\begin{array}{l}\text { Kependen } \\
\text { Return On Assets (ROA) }\end{array}$ & Raba bersih/Total Aktiva & Rasio \\
\hline $\begin{array}{l}\text { Independen } \\
\text { Pengungkapan CSR }\end{array}$ & $\begin{array}{l}\text { Banyaknya item } \\
\text { pengungkapan sosial yang } \\
\text { terdapat di laporan keuangan } \\
\text { tahunan. Jika perusahaan } \\
\text { mengungkapkan diberi skor 1 } \\
\text { (satu), namun jika tidak } \\
\text { mengungkapkan diberi skor 0 } \\
\text { (nol) Rasio }\end{array}$ \\
\hline
\end{tabular}




\begin{tabular}{|l|l|l|}
\hline & $\operatorname{CSRIj}: \frac{\Sigma \mathrm{Xij}}{\mathrm{Nj}}$ & \\
\hline
\end{tabular}

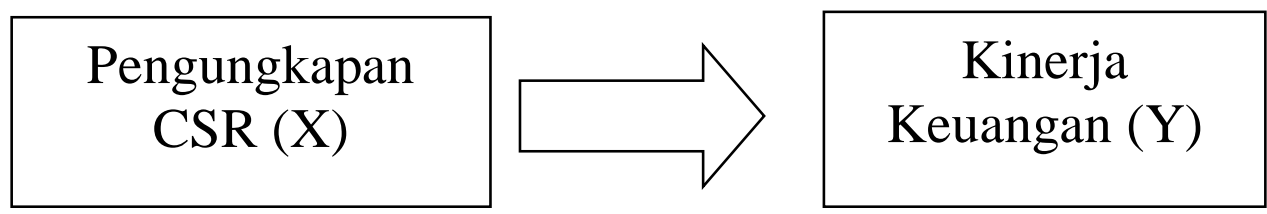

Gambar 1. Kerangka Pikir

\section{Hipotesis}

Berdasarkan kajian pustaka dan kerangka pikir, maka dapat diajukan hipotesis penelitian sebagai berikut :

H0 : $\quad$ Pengungkapan CSR tidak berpengaruh terhadap kinerja keuangan perusahaan

$\mathrm{Ha}$ : $\quad$ Pengungkapan CSR berpengaruh terhadap kinerja keuangan perusahaan

\section{HASIL DAN PEMBAHASAN}

\section{Analisis Deskriptif}

Berikut ini adalah deskripsi hasil uji statistik deskriptif Pengungkapan CSR dan ROA selama periode 2011 sampai dengan 2016 :

\section{Tabel 2. Hasil Uji Statistik DeskriptiF}

\section{Descriptive Statistics}

\begin{tabular}{|l|l|l|l|l|l|}
\hline & N & Minimum & Maximum & Mean & Std. Deviation \\
\hline $\begin{array}{l}\text { PENGUNGKAPAN_CS } \\
\text { R }\end{array}$ & 6 & 62,02 & 67,09 & 64,1817 & 2,01378 \\
\hline ROA & 6 & 4,70 & 12,52 & 9,6167 & 2,90071 \\
\hline Valid N (listwise) & 6 & & & & \\
\hline
\end{tabular}

Sumber data : Output SPSS 24

Tabel 4.3 menyajikan informasi bahwa jumlah data yang menjadi objek penelitian adalah 6 . Jumlah tersebut merupakan lama pengungkapan CSR dan ROA selama 6 tahun.

a. Corporate Social Responsibility

Varibel CSR dihitung dengan menggunakan standar GRI, membandingkan total item pengungkapan CSR perusahaan dengan indeks pengungkapan CSR. Berdasarkan hasil analisis data pada tabel 4.3 menunjukkan bahwa CSR memiliki nilai miminum sebesar 62,02 ,sedangkan nilai maksimum sebesar 67,09, nilai mean sebesar 64,3483, dan nilai standar deviasi sebesar 1,86260 .

b. Return On Assets (ROA)

Variabel ROA dihitung dengan membandingkan laba bersih dengan total aktiva. Berdasarkan analisis data pada tabel 4.1 menunjukkan bahwa ROA memiliki nilai minimum sebesar 4,70, nilai maksimum sebesar 12,52, nilai mean sebesar 9,6167 dan nilai standar deviasi sebesar 2,90071. 


\section{Uji Asumsi Klasik}

Hasil uji asumsi klasik menunjukan bahwa uji normalitas terpenuhi, dengan menggunakan uji statistik non-parametrik Kolmogorov-Smirnov (K-S) yang mana kriteria suatu data residual berdistribusi normal yaitu nilai Asymp. Sig. (2-tailed) >0,05 dan hasil menunjukan bahwa data dalam penelitian ini berdistribusi normal karena nilai nya Kolmogorov-Smirnov > 0.05 yaitu 0.133. kemudian untuk uji multikolinieritas hasil nya menunjukan bahwa antara variabel harga, dan kualitas produk tidak berkorelasi atau multikolinieritas tidak terjadi dalam model penelitian karena diperoleh nilai VIF lebih kecil dari 10 yaitu 1.000untuk variabel CSR dan ROA. Hasil uji heteroskedastisitas menunjukan bahwa tidak terjadi heteroskedastisitas karena terlihat pada titik-titik yang menyebar secara acak diatas dan dibawah angka nol (0) dan tidak membentuk suatu pola tertentu, maka dapat dikatakan bahwa regresi tidak mengalami ganguan heteroskedastisitas sehingga model regresi layak dipakai untuk memprediksi kinerja kerja berdasarkan masukan variabel bebas

\section{Gambar 2. Hasil Uji Heterokedasitisitas}

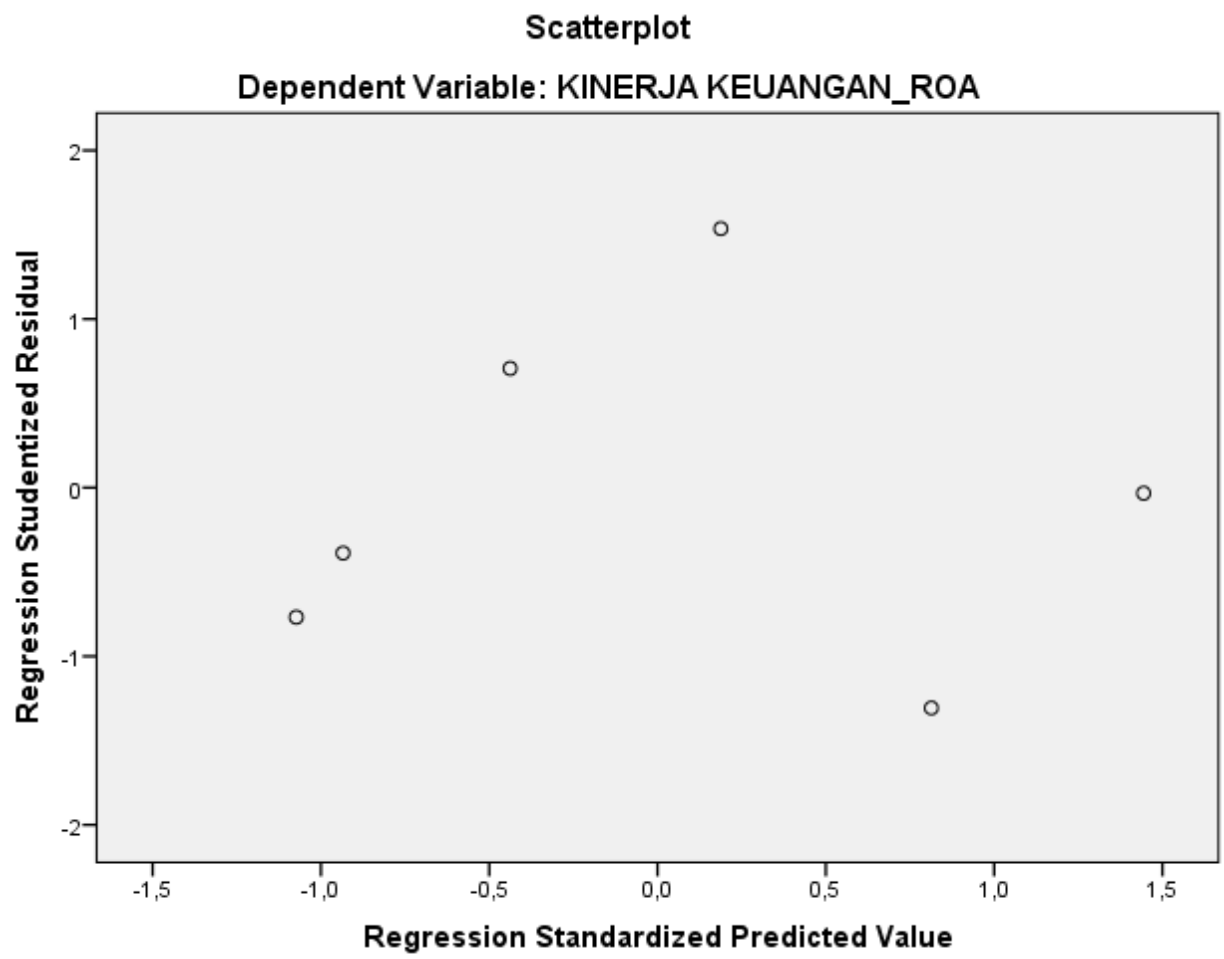

\section{Analisis Regresi}

Hasil dari analisa regresi yang dilakukan menunjukan model penelitian sebagai berikut:

$$
\mathrm{Y}=-43,702+0,888 \mathrm{X}+e
$$

Dari pengujian signifikansi uji t pada tabel 4.8 diatas menyatakan hipotesis diterima yaitu variabel independen Pengungkapan CSR mempengaruhi ROA, karena memiliki nilai t hitung > t tabel, dengan nilai signifikansi $<0,05$. Nilai t hitung Pengungkapan CSR terhadap ROA sebesar 3,602 > nilai t tabel 2,776, dengan nilai signifikansi $0,023<0,05$. 
Tabel 3. Hasil Uji Signifikansi Parsial (Uji Statistik t)

\section{Coefficients $^{\mathbf{a}}$}

\begin{tabular}{|c|c|c|c|c|c|c|}
\hline \multirow{2}{*}{\multicolumn{2}{|c|}{ Model }} & \multicolumn{2}{|c|}{$\begin{array}{l}\text { Unstandardized } \\
\text { Coefficients }\end{array}$} & \multirow{2}{*}{$\begin{array}{l}\text { Standardized } \\
\text { Coefficients } \\
\text { Beta }\end{array}$} & \multirow[b]{2}{*}{$t$} & \multirow[b]{2}{*}{ Sig. } \\
\hline & & $\mathrm{B}$ & Std. Error & & & \\
\hline \multirow[t]{2}{*}{1} & (Constant) & $-43,702$ & 15,825 & & $-2,762$ & 051 \\
\hline & $\begin{array}{l}\text { PENGUNGKAPAN } \\
\text { CSR }\end{array}$ &, 888 & ,246 &, 874 & 3,602 &, 023 \\
\hline
\end{tabular}

a. Dependent Variable: KINERJA KEUANGAN_ROA

Sumber: Hasil Output SPSS 24

\section{Pengujian Hipotesis}

Dalam penelitian ini, penulis mengajukan hipotsesis penelitian sebagai berikut:

Ho : Pengungkapan CSR tidak berpengaruh terhadap kinerja keuangan perusahaan.

$\mathrm{Ha}$ : Pengungkapan CSR berpengaruh terhadap kinerja keuangan perusahaan.

Hasil uji hipotesis pada penelitian ini dapat dilihat pada tabel 4.9, variabel pengungkapan CSR terhadap kinerja keuangan yang di-proxy dengan ROA mempunyai nilai $t$ hitung sebesar 3,602 dengan tingkat signifikan 0,023 lebih kecil dari 0,05. Hal ini menunjukkan bahwa pengungkapan CSR berpengaruh terhadap kinerja keuangan, dengan demikian Ha diterima.

\section{Uji Simultan (Uji F)}

Hasil dari uji simultan dapat diketahui nilai $\mathrm{F}$ hitung 12,978 > F tabel 6,61, dengan nilai signifikansi sebesar $0,023<0,05$, dengan demikian dapat disimpulkan bahwa model yang digunakan untuk menguji pengungkapan CSR adalah model yang fit dan berpengaruh signifikan terhadap ROA.

\section{Tabel 4. Hasil Uji Koefisien Determinasi}

Model Summary ${ }^{b}$

\begin{tabular}{|l|l|l|l|l|}
\hline & & & & \\
Model & $\mathrm{R}$ & R Square & Adjusted R Square & $\begin{array}{l}\text { Std. Error of the } \\
\text { Estimate }\end{array}$ \\
\hline 1 &, $874^{\mathrm{a}}$ &, 764 &, 705 & 1,10982 \\
\hline
\end{tabular}

a. Predictors: (Constant), PENGUNGKAPAN CSR

b. Dependent Variable: KINERJA KEUANGAN_ROA

Sumber data: Hasil Output SPSS 24

Berdasarkan hasil data pada tabel 4.7 menunjukkan bahwa nilai Adjusted $R$ Square variabel CSR dan kinerja keuangan yang diproxy dengan ROA sebesar 0,705 atau sebesar 70,5\%. Hal ini menunjukkan bahwa sebesar 70,5\% variabel Return On Assets perusahaan dapat dijelaskan oleh variabel pengungkapan tanggung jawab sosial, sedangkan sisanya sebesar 29,5\% dijelaskan oleh faktor-faktor lain. 


\section{PEMBAHASAN}

Berdasarkan output SPSS, hasil penelitian ini menunjukkan bahwa variabel pengungkapan CSR berpengaruh terhadap kinerja keuangan. Hasil penelitian ini menunjukkan bahwa besar kecilnya pengungkapan CSR mempengaruhi dalam tingkat kinerja keuangan. Hasil penelitian ini didukung dengan penelitian Brine, et al (2007) dalam penelitiannya menjelaskan bahwa penerapan CSR mempengaruhi kinerja keuangan ROA. Sulastini (2007) menyatakan bahwa profitabilitas merupakan faktor yang memberikan kebebasan dan fleksibelitas kepada manajemen untuk mengungkapkan pertanggungjawaban sosial kepada pemegang saham. Hal ini berarti semakin tinggi tingkat profitabilitas perusahaan maka semakin besar pengungkapan informasi sosial.

\section{PENUTUP}

Penelitian ini dilakukan untuk mengetahui apakah terdapat pengaruh antara pengungkapan CSR dengan kinerja keuangan. Untuk menentukan perusahaan melakukan pengungkapan tanggung jawab sosial atau tidak melakukan, dapat dilihat dari indeks GRI (Global Reporting Initiative) berdasarkan guidelines tahun 2009. Sedangkan untuk menilai kinerja keuangan, peneliti menggunakan rasio probabilitas ROA (Return On Assets). Berdasarkan hasil penelitian bahwa pengungkapan corporate social responsibility (CSR) memiliki pengaruh positif signifikan terhadap kinerja keuangan PT Asahimas Flat Glass Tbk.

SARAN

Berdasarkan hasil penelitian dan hal-hal yang berkaitan dengan keterbatasan penelitian, maka terdapat beberapa hal yang harus diungkapkan :

1. Bagi manajemen perusahaan diharapkan lebih terbuka untuk melakukan pengungkapan kegiatan-kegiatan yang berhubungan dengan tanggung jawaab sosial dan lingkungan dalam laporan tahunannya.

2. Bagi pemerintah dan IAI diharapkan mampu merumuskan suatu kebijakan untuk menjadikan pengungkapan tanggung jawab sosial dan lingkungan perusahaan sebagai sebuah mandatory disclosure mengingat rendahnya tingkat pengungkapan tanggung jawab sosial.

3. Bagi investor hendaknya memperhatikan laporan pertanggung jawaban sosial dan lingkungan perusahaan guna dalam mengambil keputusan.

4. Penelitian selanjutnya diharapkan dapat menambah jumlah sampel yang lebih besar, sehingga hasil yang diperoleh lebih meyakinkan.

5. Penelitian selanjutnya diharapkan dapat menambahkan variabel lainnya untuk menemukasn suatu model standar pengungkapan tanggung jawab sosial dan lingkungan perusahaan.

\section{REFERENSI}

Adityo, 2012, Analisis Pengaruh Corporate Social Responsibility, Beta, Firm, Size, dan Boook Market Ratio tehadap Return Saham (Studi Kasus Perusahaan Manufaktur yang Terdaftar di BEI Periode 2010 - 2011)", Skripsi. Semarang : Fakultas Ekonomi UNDIP.

Anggraini, Retno, 2006, Pengungkapan Informasi Sosial dan Faktor- Faktor yang Mempengaruhi Pengungkapan Informasi Sosial Dalam Laporan Keuangan Tahunan (Studi Empiris pada Perusahaan-perusahaan yang terdaftar BEJ).Simposium Nasional IX Padang.

Brigham, Eugene F and Joel F.Houston, 2006, Dasar-dasar Manajemen Keuangan, terjemahan Ali Akbar Yulianto dari Fundamental of Management 2004, Jakarta : Salemba Empat.

Cahya, 2010, Analisis Pengaruh Kinerja Keuangan Terhadap Tanggung Jawab Sosial Perusahaan (Studi pada Bank di Indonesia periode tahun 2007-2008), Skripsi, Semarang : Universitas Diponegoro.

Dewanggono H.K., Ratih, 2011, "Pengaruh Pengungkapan Tanggung Jawab Sosial Perusahaan dalam Laporan Tahunan terhadap Harga Saham”. Skripsi. Semarang : Fakultas Ekonomi UNNES. 
Ghozali Imam, 2011, Analisis Multivariate dengan Program SPSS, Semarang : Badan penerbit Universitas Diponegoro.

GRI, 2012, Suistainability Reporting Guidelines G3, https://www.globalreporting.org/, pada tanggal 29 September 2009.

Hadi, Noor, 2011, Corporate Social Responsibility, Yogyakarta : Graha Ilmu.

Hariyanto, Agus. 2009. Membuat Anak Cepat Pintar Membaca. Jogjakarta: Diva Press.

Indrawan, Danu Candra, 2011, Pengaruh Corporate Social Responsibility terhadap Kinerja Perusahaan. Skripsi. Semarang : Fakultas Ekonomi UNDIP.

Irham Fahmi, 2014, Analisis Kinerja Keuangan, Bandung : Alfabeta Cv.

Kusumadilaga, Rimba, 2010, Pengaruh Corporate Social Responsibility Terhadap Nilai Perusahaan dengan Profitabilitas sebagai Variabel Moderating (Studi Empiris pada Perusahaan Manufaktur yang terdaftar di BEI), Semarang : Universitas Diponegoro.

Mardikanto, Prof. Dr. Ir. Totok, M.S, 2014, Corporate Social Responsibility (Tanggungjawab Sosial Korporasi), Bandung Alfabeta Cv.

Probo, Endro, 2009, Peran CSR dalam Perusahaan. Dari http://antrounair.wordpress.com/2008/08/19/peran-csr-dalam-perusahaan/

Pernyataan Standar Akuntansi Keuangan (PSAK) No.1 tahun 2009 tentang Penyajian Laporan Keuangan.

Purba, Marisi. P, 2007, Aspek Akuntansi Undang-Undang Perseroan Terbatas, Yogyakarta : Graha Ilmu.

Putra, Rianto Adi, 2013, Pengaruh Ukuran Perusahaan dan Profitabilitas terhadapNilai Perusahaan. Skripsi. Fakultas Bisnis :Universitas Kristen Duta Wacana.

Putri, Okta Prastika Utomo, 2014, "Peran Profitabilitas sebagai Moderating Variabel dari Pengaruh Corporate Social Responsibility terhadap Nilai Perusahaan (Studi Empiris Perusahaan Manufaktur yang Terdaftar di BEI).Jurnal. Semarang : Universitas Dian Nuswantoro

Rangkuti, Freddy. 2005. The Power of Brand's. Gramedia Pustaka Utama: Jakarta.

Sugiyono, 2007,Metode Penelitian Bisnis, Bandung: CV Alfabeta.

Undang-Undang Republik Indonesia Nomor 25 tahun 2007 tentang Penanaman Modal.

Undang-Undang Republik Indonesia Nomor 40 tahun 2007 tentang Perseroan Terbatas. Jakarta.

Wati, L.N. 2018. Faktor-Faktor yang Mempengaruhi Pengungkapan Corporate Social Responsibility Dengan GRI 3. Jurnal Ecodemica, Vol. 2 No. 2. Pp 240-252.

Yusuf Wibisono, 2007, Membedah Konsep \& Aplikasi CSR (Corporate Social Responsibility), PT Gramedia, Jakarta

Yuniarti, Eti, 2007, Analisis Pengungkapan Informasi Tanggung Jawab Sosial pada Sektor Perbankan di Indonesia, Semarang : Universitas Diponegoro.

Yuniasih, Ni Wayan, dan Made Gede Wirakusuma, 2007, "Pengaruh Kinerja Keuangan terhadap Nilai Perusahaan dengan Pengungkapan Corporate Social Responsibility dan Good Corporate Governance sebagai Variabel Pemoderasi,” Jurnal Akuntansi. Universitas Udayana. 